\title{
Retrobulbar Hematoma in Blow-Out Fracture after Open Reduction
}

\author{
Ji Seon Cheon, Bin Na Seo, Jeong Yeol Yang, Kyung Min Son \\ Department of Plastic and Reconstructive Surgery, Chosun University College of Medicine, Gwangju, Korea
}

Retrobulbar hemorrhage, especially when associated with visual loss, is a rare but significant complication after facial bone reconstruction. In this article, two cases of retrobulbar hematoma after surgical repair of blow-out fracture are reported. In one patient, permanent loss of vision was involved, but with the other patient, we were able to prevent this by performing immediate decompression after definite diagnosis. We present our clinical experience with regard to the treatment process and method for prevention of retrobulbar hematoma using a scalp vein set tube and a negative pressure drainage system.

Keywords Orbital fractures / Retrobulbar hemorrhage / Orbit

\author{
Correspondence: Jeong Yeol Yang \\ Department of Plastic and \\ Reconstructive Surgery, Chosun \\ University College of Medicine, 365 \\ Pilmun-daero, Dong-gu, Gwangju \\ 501-717, Korea \\ Tel: +82-62-220-3180 \\ Fax: +82-62-225-0996 \\ E-mail: jyyang@chosun.ac.kr
}

This article was presented as a poster at the 2nd Research and Reconstructive Forum on June 1-2, 2012 in Gwangju, Korea.

This study was supported by research funds from Chosun University Hospital, 2011.

No potential conflict of interest relevant to this article was reported.

Received: 14 Mar 2013 • Revised: 19 May 2013 • Accepted: 24 Jun 2013

pISSN: 2234-6163 • elSSN: 2234-6171 • http://dx.doi.org/10.5999/aps.2013.40.4.445• Arch Plast Surg 2013;40:445-449

\section{INTRODUCTION}

Retrobulbar hematoma is a condition that involves blood congestion deep in the soft tissue of the posterior orbital septum. Although this is a rare complication, it requires considerable caution because it can cause blindness. It may occur not only due to trauma, facial fracture surgery, and peri-orbital surgery such as blepharoplasty, but also after circumbulbar anesthesia. Most of these conditions are known to occur within 24 hours after surgery $[1,2]$.

The retrobulbar hematoma seems to result from bleeding caused by damage to the infra-orbital arteries or the anterior and posterior ethmoidal arteries during surgery and rebound vasodilation of the vascular puncture site upon injection $[3,4]$.
It usually comes secondary to sustained orbital bleeding after wound closure. Though the exact mechanism of the visual loss is not fully understood, it is assumed that it is the result of interference with the blood supply [5].

In our class, in 2006 to 2011, a total of 1,180 cases of blowout fracture surgery were performed, and a total of two cases of retrobulbar hematoma were experienced in 2011 alone. The incident had not been experienced before, from 2006 to 2010 . Among these two cases, one involved permanent loss of vision. In the remaining case, the authors were able to prevent the loss of sight by performing immediate decompression after definite diagnosis. The authors hereby report and analyze these cases, as well as review the literature on the clinical skills needed for prevention of retrobulbar hematoma.

Copyright $(\odot 2013$ The Korean Society of Plastic and Reconstructive Surgeons

This is an Open Access article distributed under the terms of the Creative Commons Attribution Non-Commercial License (http://creativecommons.org/

licenses/by-nc/3.0/) which permits unrestricted non-commercial use, distribution, and reproduction in any medium, provided the original work is properly cited. 


\section{CASES}

\section{Case 1}

A healthy 20-year-old man complained of discomfort in his left eye caused by assault. His visual acuity and intra-ocular pressure were normal. The physical examination showed no signs of diplopia or gaze limitation. However, since there were computed tomography (CT) findings of an approximately $21 \mathrm{~mm} \times 18$ $\mathrm{mm}$ fracture, and trapping of the ocular content and the inferior rectus muscle accompanied by displacement of the left orbital floor (Fig. 1), orbital wall reconstruction was performed using a re-absorptive polymer mesh (Floor liner, Medtronic, Minneapolis, USA) seven days after the injury. It was performed without difficulty and there was little bleeding in the operation field. The light reflex in both eyes was normal after the surgery, and there were no specific ocular symptoms other than subconjunctival hemorrhage (Fig. 2). On the fifth day, the patient's visual acuity and intra-ocular pressure were restored to preoperative levels, so the patient was discharged without any specific symptoms. Ten days after the reconstruction, the patient visited our hospital complaining of loss of sight two to three days earlier. The patient considered the symptom temporary following surgery, and there were no accompanying symptoms such as pain. As for the visual acuity, the patient did not perceive light and was positive for relative afferent papillary defect. His intra-ocular pressure was normal, and there were no specific findings during the ophthalmic examination. A CT scan was immediately performed.

Fig. 1. Preoperative coronal computed tomography scan of a 20-year-old male

Displacement of the left orbit floor was seen (red arrow).

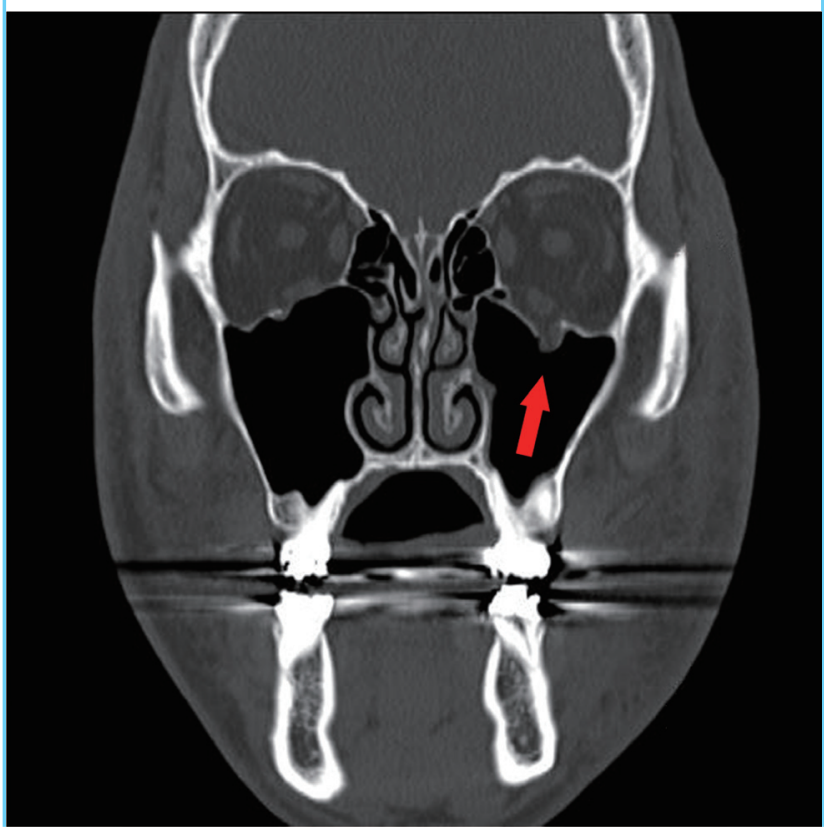

Since retrobulbar hematoma up to the apex was observed (Fig. $3)$, the authors immediately removed and decompressed the hematoma and started systemic steroid therapy $(250 \mathrm{mg}$ per 6 hours of methylprednisolone for three days, and steroid tapering). However, there was no visual recovery.

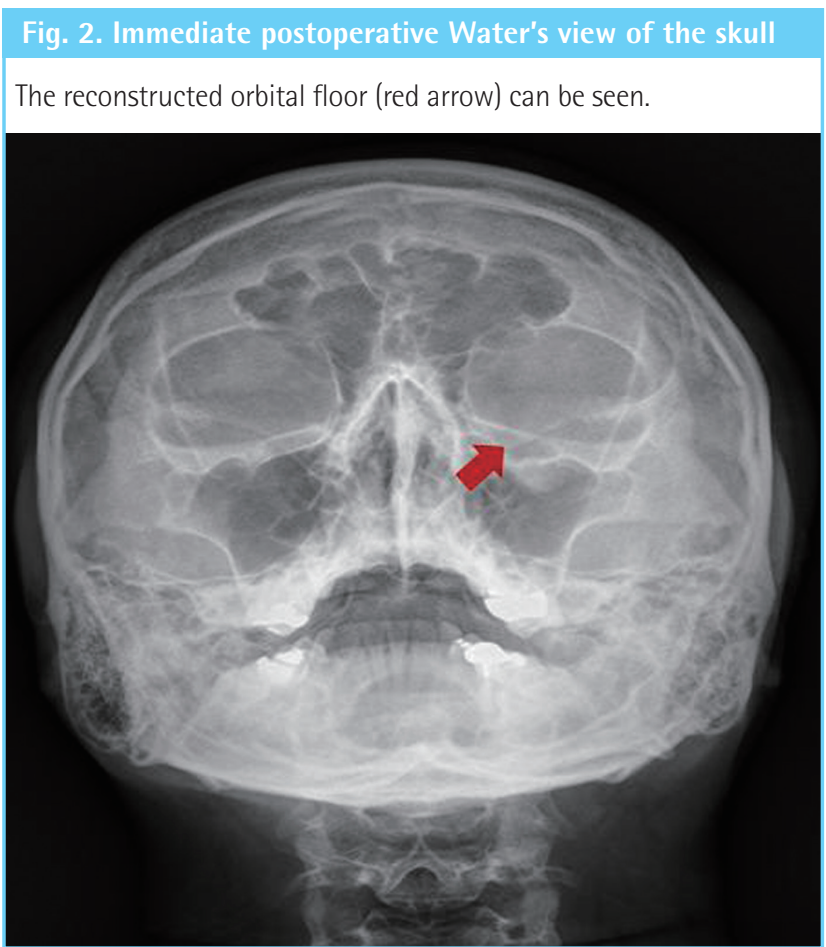

Fig. 3. Computed tomography scan, 10 days after surgery

Retrobulbar hematoma, extended into the apex, was found on the left inferior orbital wall (red arrow), and slight deviation of the optic nerve was seen.

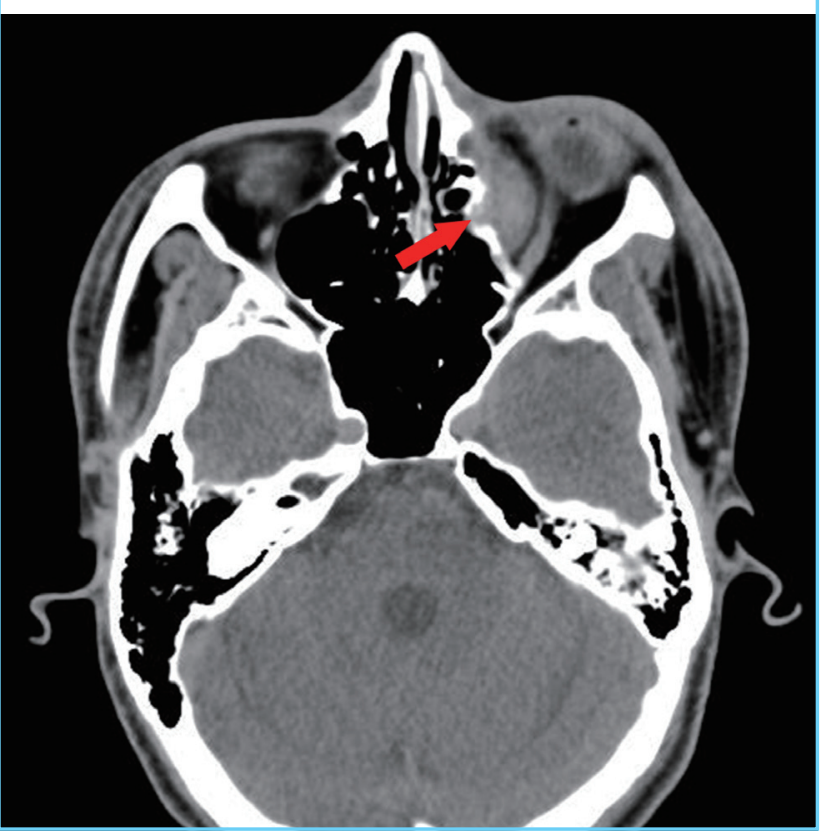




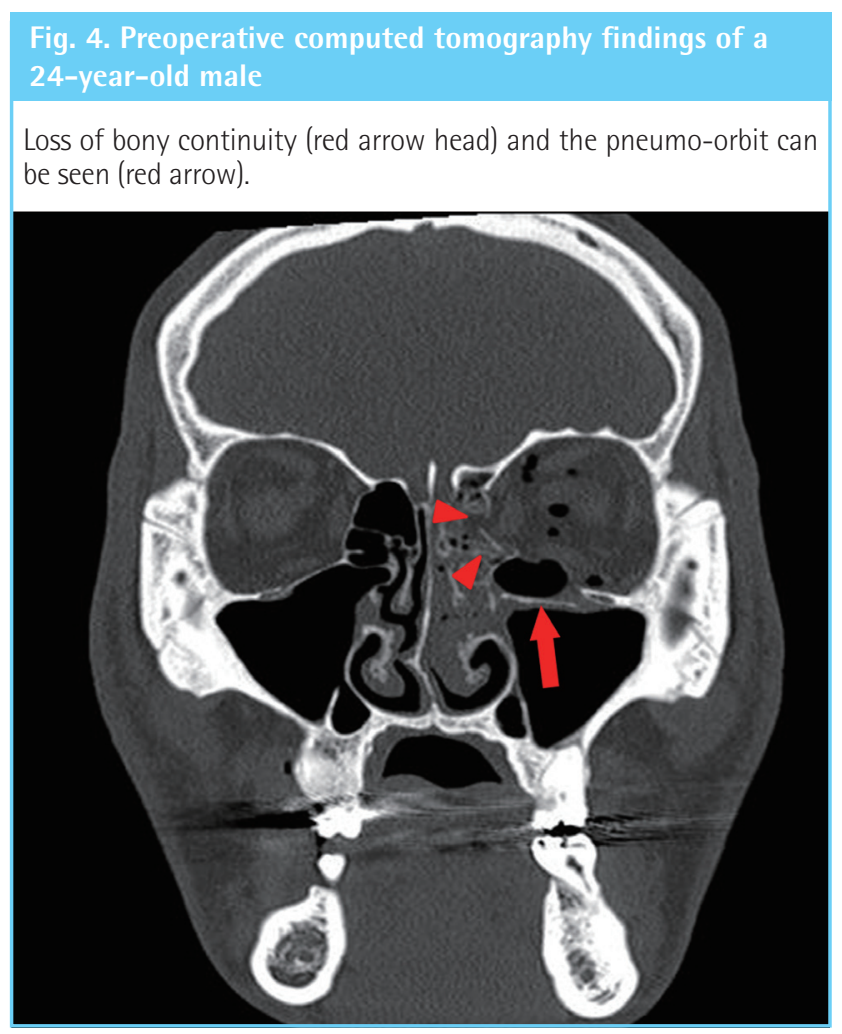

Case 2

A healthy 24-year-old man fell and struck his left eye prior to admission. His visual acuity and intra-ocular pressure were normal. The CT scan revealed approximately $25 \mathrm{~mm} \times 21 \mathrm{~mm}$ and $18 \mathrm{~mm} \times 15 \mathrm{~mm}$ fractures, and pneumo-orbits of the left orbit medial wall and floor, respectively (Fig. 4). There was also a $2 \mathrm{~mm}$ enophthalmos on his left eye. Orbit wall reconstruction was performed using porous polyethylene (Medpor, Howmedica Osteonics, Newnan, USA) on the eighth day after the injury. The visual acuity and light reflex in both eyes were normal after the surgery. About 29 hours after the orbit wall reconstruction, the patient suddenly complained of blurred vision, mild pain, bulbar pressure, and circumbulbar hardness without any precipitating factors. Due to the observation of ecchymosis in the medial canthal area and of subconjunctival hemorrhage, retrobulbar hematoma, and significant proptosis in a CT scan (Fig. 5), emergency surgery was performed within one hour of the manifestation of the symptoms. An active bleeding point was not observed during the exploration. However, decompression was performed through hematoma drainage after the region of the suspected microbleeding was gently cauterized with hemostatic forceps. A scalp vein set tube was located and fixed in the reduced fracture region. A suction drain was connected and continuously drained during the surgery. Afterwards, a negativepressure syringe was connected to enable drainage. The pain was immediately reduced and the vision improved after the sur-

\section{Fig. 5. Computed tomography scan about 29 hours after} surgery

Retrobulbar hematoma (red arrow) and proptosis (red arrow head) was found. The optic nerve was compressed by formation of the retrobulbar hematoma (red arrow).

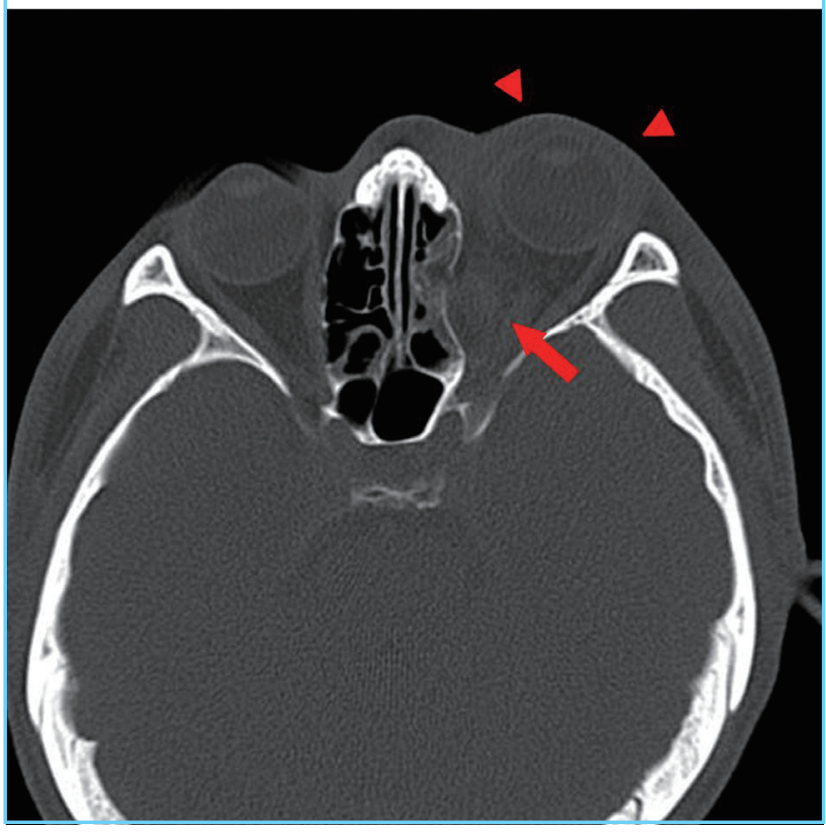

gery, and the eyeball movement, visual acuity, and intra-ocular pressure remained normal during the follow-up period.

\section{DISCUSSION}

Retrobulbar hematoma occurs due to orbital trauma, circumorbital surgery, and various forms of intra-orbital surgery. It requires caution because it can cause visual impairment or blindness by inducing optic nerve ischemia, retinal necrosis, and vasospasm of the retina artery through increased intra-ocular pressure $[2,5,6]$. Because of the anatomical structure of the cone-shaped orbit, edema and hematoma of the circumbulbar tissue can easily occur if there is no complete hemostasis. This is attributed to the possible increase in pressure in the orbital apex [6]. Decompression is normally carried out while drainage occurs through the maxillary or ethmoid sinus, but blocking off of such a drainage path due to soft tissue impaction or tearing of the peri-orbita as a result of trauma may cause blockage [5]. In addition, the effort to completely cover the fracture site may have eliminated free drainage of blood into the sinus cavity.

In 1950, Gordon and Macrae [7] first reported a case of blindness as a complication of retrobulbar hematoma after zygomatic bone surgery, while Nicholson and Guzak [8] reported two cases of retrobulbar hemorrhage that occurred in 72 cases of orbital fracture surgery over five years. Ord et al. [5] reported a 
$0.28 \%$ prevalence of retrobulbar hematoma $(4 / 1,405)$ in seven years, and Girotto et al. [9], a $0.32 \%$ prevalence $(4 / 1,240)$ in 11 years. In Korea, Lee et al. [10] reported a $0.39 \%$ prevalence $(5 / 512)$ of retrobulbar hematoma in five years, and stated that bleeding may occur as a result of vascular injury during needle injection when approached through a subciliary incision during orbital surgery or damage to adjacent blood vessels upon bone reduction. A total of 1,180 cases of orbital wall reconstruction were performed in 2006 to 2011 at our hospital, and two cases $(0.16 \%)$ of retrobulbar hematoma were experienced.

When retrobulbar hematoma occurs, the patient may show ocular symptoms such as circumbulbar pain and pressure, proptosis, eyelid discoloration, mydriasis, visual impairment, and diplopia. Symptoms of increased intra-ocular pressure that include nausea, vomiting, and headache may also be present $[1,5,8]$. Therefore, patients who manifest these symptoms after surgery require definite diagnosis through a CT scan. Loss of sight can be prevented only when medical or surgical decompression is performed within at least 24 hours immediately after the diagnosis $[9,10]$. Moreover, prevention can be very important. Starting from a thorough investigation of the patient's history including his aspirin intake and whether or not he had hypertension and blood and vascular disease before the surgery, thorough hemostasis, continuous pressure on the eyeball, and excessive manipulation must be avoided during the surgery. Implants that have an appropriate size and shape for covering the defective region must be used [2,8]. In addition, continuous follow-ups and check-ups on the pain, proptosis, vision, and pupil reflex must be carried out after surgery not only by the medical staff but also by the patient and his guardian. Similar to our first case, delayed hemorrhage may occur, so a self-vision test with a vision check card is required $[2,8]$.

However, there was no notable medical history and no difficulty in incision, dissection, exposure of the fracture site, insertion of the implant, or closure during the surgery for either of the patients reported here. Furthermore, surgery was performed with as little trauma as possible during retraction of the orbital contents and sharp dissection within the orbit was kept at a minimum and done only under direct vision. The implants were found to be in the original site during the second exploration. The surgery went smoothly and did not take over 40 minutes in either case. Therefore, the negative pressure drainage system using the scalp vein set tube that was used at our hospital was assumed to have been helpful. We had used negative-pressure drainage tubes only for the patients who reported excessive bleeding or unclear bleeding points after hemostasis prior to 2011, and no significant problems had been reported. After experiencing two cases of retrobulbar hematoma with success- ful intraoperative hemostasis, and without surgical problems in 2011, we have routinely inserted a negative-pressure drainage tube that has three or four holes in its end using a scalp vein set during orbital surgeries. After the end of the punctured scalp vein set tube was located on the reduced orbital wall, it was continuously drained by connecting a suction drain tube during the surgery. Suture was performed on the periosteum and the skin, and the tube was tagged to the peri-orbital skin. After surgery, drainage was enabled by connecting a negative-pressure syringe. By maintaining it for 1 to 2 days, the authors obtained good results without specific complications (Fig. 6). According to a survey targeting 488 patients, the mean drainage amount was $7.9 \mathrm{~mL}$ during 2 days postoperatively. Considering the limited intraorbital space and postoperative edema, the volume is thought to be large enough to form hematoma and a consequent compression of the optic nerve if not drained via normal channels. Therefore, these conditions may be a rationale for the routine use of the negative-pressure drainage tube we use. There

\section{Fig. 6. Application of the negative pressure syringe \\ (A) An immediately postoperative view of the patient with the scalp vein set tube, which was connected to a negative syringe after surgery. (B) A magnified view of the negative pressure syringe using the scalp vein set tube with 3 side holes (red arrow heads).}
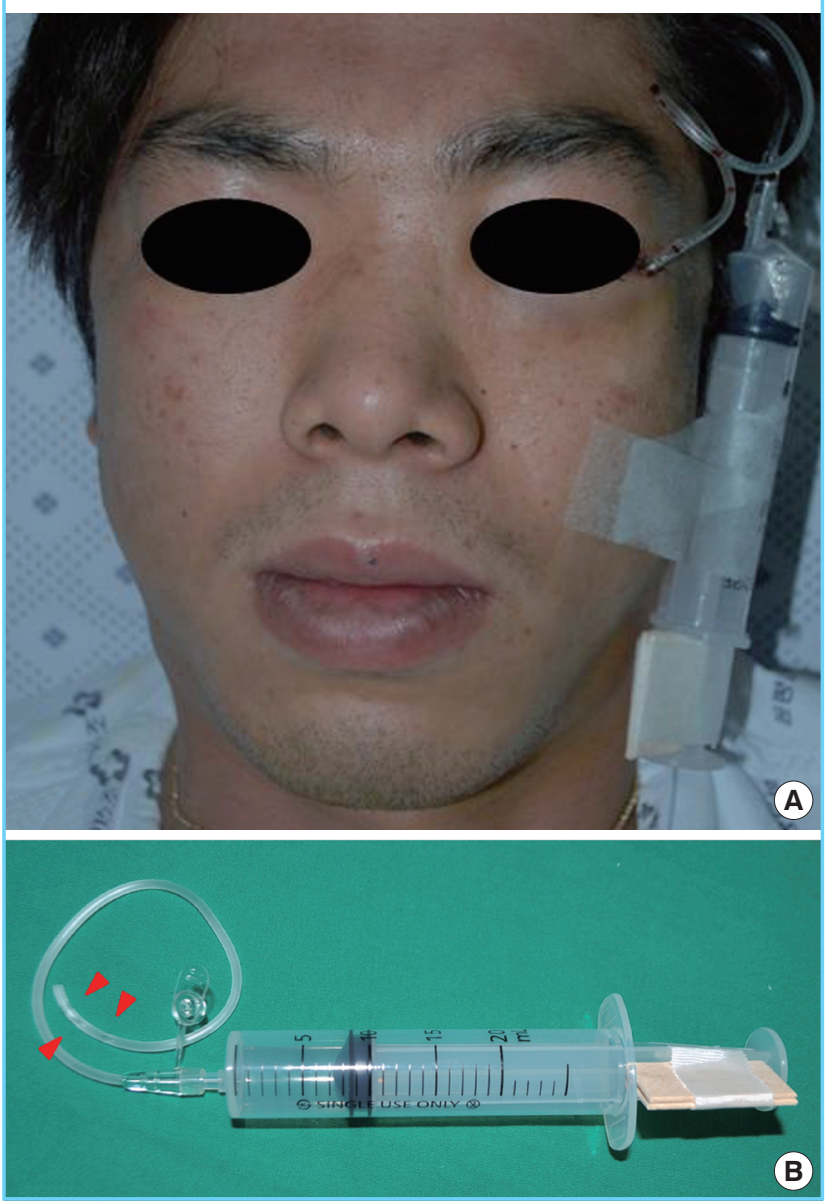
have been previous reports of negative pressure drainage using a vacuum tube [11]. However, we herein report negative pressure drainage using a syringe, which is more economical, easier to use in the operating room, easier for checking the amount of drainage, and which can control the pressure.

Finally, conservative treatment is also important after surgery. Procedures include avoidance of a semi-Fowler position, application of an icepack, and avoidance of Valsalva manipulation that would apply excessive force during coughing, vomiting, or bowel movement, which would increase the intra-ocular pressure. Although retrobulbar hematoma is a very rare complication of blow-out fracture surgery, it may have severe consequences including visual loss. Therefore, caution, prompt diagnosis, and immediate treatment are required. In addition, routine use of the negative-pressure drainage system with the use of the scalp vein set tube is expected to help prevent the event, as reported in this paper based on a literature review.

\section{REFERENCES}

1. Hass AN, Penne RB, Stefanyszyn MA, et al. Incidence of postblepharoplasty orbital hemorrhage and associated visual loss. Ophthal Plast Reconstr Surg 2004;20:426-32.

2. Liu D. Blindness after blow-out fracture repair. Ophthal Plast Reconstr Surg 1994;10:206-10.
3. Kang JS. Plastic surgery. 3rd ed. Daegu: Koonja; 2004.

4. Teng CC, Reddy S, Wong JJ, et al. Retrobulbar hemorrhage nine days after cosmetic blepharoplasty resulting in permanent visual loss. Ophthal Plast Reconstr Surg 2006;22:388-9.

5. Ord RA, Awty MD, Pour S. Bilateral retrobulbar haemorrhage: a short case report. Br J Oral Maxillofac Surg 1986;24: 1-6.

6. Choi JI, Lee SP, Ji SY, et al. Nerve injuries after the operations of orbital blow-out fracture. J Korean Cleft Palate-Craniofac Assoc 2010;11:28-32.

7. Gordon S, Macrae H. Monocular blindness as a complication of the treatment of malar fracture. Plast Reconstr Surg (1946) 1950;6:228-32.

8. Nicholson DH, Guzak SW. Visual loss complicating repair of orbital floor fractures. Arch Ophthalmol 1971;86:369-75.

9. Girotto JA, Gamble WB, Robertson B, et al. Blindness after reduction of facial fractures. Plast Reconstr Surg 1998;102: 1821-34.

10. Lee SW, Choi YW, Nam SH, et al. Delayed retrobulbar hemorrhage after orbital floor reconstruction. J Korean Soc Plast Reconstr Surg 2010;37:489-91.

11. Lee DG. Idea on prevention from postoperative intraorbital hematoma in orbital surgery. Indian J Otolaryngol Head Neck Surg 2012:1-3. 